\title{
Benford's Law As a Useful Tool to Determine Fraud in Financial Statements
}

\author{
MATEJA GORENC \\ International School of Social and Business Studies, Slovenia \\ mateja.gorenc@gmail.com
}

\begin{abstract}
Benford's law is a mathematical tool and a method of determining whether investigated financial statements contain unintentional errors or fraud. Benford's law says that counterfeit numbers have a slightly different pattern than valid or random samples. Benford's Law is an effective method and analytical technique to help detect accounting fraud. Motives and causes for fraud can be explained by the fraud triangle, which consists of percieved pressure, perceived opportunities and the ability to justify their actions. Benford's law is just one of the possible tools used to detect irregularities, which can also be used in the field of data verification in financial statements.
\end{abstract}

Key words: Benford's law, accounts, fraud, fraud triangle, forensic accounting, forensic accountant

https://doi.org/10.26493/1854-4231.14.19-31

\section{Introduction}

In recent years, there has been a lot of fraud committed across the globe and in Slovenia. Businesses used the lack of rules and regulations related to the prevention and management of accounting fraud for their own benefit. Soon after the great world scandals, new laws, regulations, rules and models of practice for the prevention and detection of fraud appeared. The result of fraud is mainly a financial scandal, which can result from a deliberate misrepresentation or misidentification of items or improper use of the company's assets. This is, therefore, a deliberate use of creative methods that, in one way or another, affects an income statement, either with overvalued revenues, undervalued costs, overvalued assets or others.

If the information in the financial statements is reliable or credible, Benford's law can be used as a quick test, which shows us the expected frequency distribution of the digits in each report. If the first digits are distributed in a different way than they should be, then, on the basis of the test, we can suspect the existence of fraud or an error. This is not enough to prove fraud in court (Hladnik 2002, 
147). The company's management is responsible for the detection and prevention of fraud and a key role is played by auditors and forensic accountants. The latter also deal with proving instances of fraud. The aforementioned problem was examined abroad by Nigrini (2012), and Skitek (2000) in Slovenia.

\section{Fraud in Financial Statements}

The International Standards on Auditing (Mednarodni standard revidiranja 2009) define fraud as a misstatement arising from the embezzlement of assets and misstatements resulting from fraudulent financial reporting. Fraud is a deliberate act committed by one or more people (usually members of the company's management) in order to gain certain benefits in an unlawful and unjust manner. Fraud covers the following items (p. 7):

- alteration, falsification or adjustment of records or documents,

- unlawful appropriation of funds,

- concealing or abandoning the effects of business events in records and documents,

- recording business events that did not happen,

- misusing accounting rules.

The reasons for fraudulent financial reporting are very different. They are mainly affected by the constant pressure exerted by the organization over its employees, the opportunities for fraud occurring at a given moment, and the individuals' immoral values (Mednarodni standard revidiranja, 2009, 17-18). In addition, the organization also experiences pressure from the public, international business guidelines and strong competition.

According to ACFE, fraud is divided into three main groups, namely, (1) fraud related to corruption, (2) fraud related to fixed assets, and (3) fraud in financial statements. If we take a closer look at the financial statements, we are talking about undervalued and overvalued net income (ACFE 2014). Koletnik and Kolar $(2008,45)$ defined fraudulent financial reporting as manipulation, falsification, falsification or alteration of accounting records; misrepresentation or the deliberate omission of events, transactions or other relevant information in the financial statements; intentionally misapplied accounting rules, principles and standards. Therefore, fraudulent financial reporting is a deliberate misstatement or omission in the financial statements of companies in order to mislead the users of financial statements (Nigrini 2012, 125). 
FIGURE 1

Fraud Triangle by Creesey (adapted from Koletnik and Kolar 2008, 42)

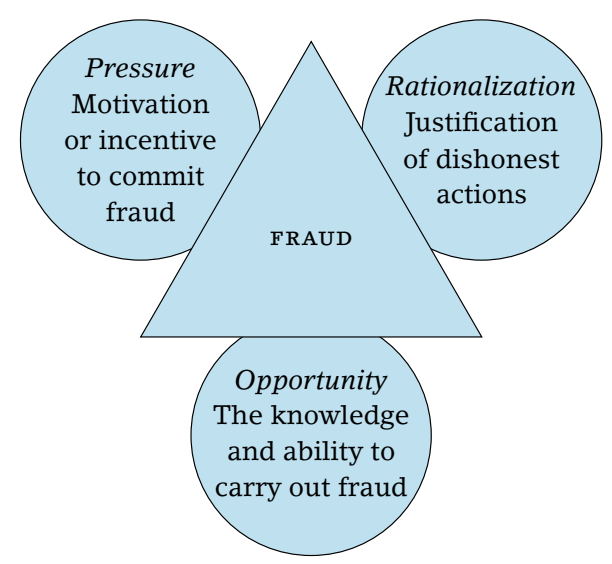

Different types of fraud can be committed in order to obtain material or other benefits. The most common causes of fraud are opportunity, pressure and the misinterpretation of actions (Skitek 2000, 8-9). The incentive factors for the occurrence of fraud are, among others, the inclination of individuals to commit fraudulent acts, pressure on management and a wasteful life (Koletnik 2009, 253-54). Creesey (1919-1987) was engaged in the investigation of economic crime caused by top managers in the area of fraud. The result of his research is the so-called 'Fraud Triangle' that tells people that they are doing bad things when simultaneously there is a relationship of three factors - opportunity, pressure and rationalization (Koletnik and Kolar 2008, 33).

Figure 1 shows Creesey's Fraud Triangle. One axis of the triangle represents the perceived indivisible pressure of a financial problem. On the second axis, there is the perceived opportunity to solve the financial problem. The final axis represents the rationalization between the perceived problem and the opportunity (Koletnik and Kolar 2008, 42).

There are many reasons for the falsification of accounting data on the part of managers who pressure accountants to show a desired economic picture through the financial statements, in particular, the desired profit or loss, taking into account unauthorized adjustments of revenue and/or expenses. Similarly, motives can be on the part of owners and their expectations (Koletnik and Kolar 2008, 154). Reasons for the emergence of economic crime can be found both inside and outside of companies. The internal reasons are, in particular, the moral of the individual and his predisposition to fraud, the attitude of management to fraud, access to accounting and other records, ac- 
counting solutions and company assets. The external reasons mainly refer to the poor social status of individuals and to ineffective social control (Koletnik and Kolar 2008, 36).

\section{Benford Law}

Benford's law has many uses. One of the most popular is the detection of fraud and data falsification. This is due to the simple fact that unfalsified data is usually sufficient to Benford's first significant digit; however, falsified data such as duplicate payments or forged ballot papers in elections do not suffice. In most cases, people choose random numbers in a fairly uniform pattern, but the actual data does not always follow this. The method is widespread in banking and accounting; Nigrini and Mittermaier (1997) wrote about its forensic use. Abroad, auditors successfully apply Benford's law in their work; in our country, its use is still unknown and very rarely seen in practice $(S k i t e k 2000,11)$. The task of the auditor is to determine the reasons for the deviation of an analysis of investigated data from Benford's law (Skitek 2000, 12).

\section{THE CREATION AND INTRODUCTION OF BENFORD'S LAW}

The story of the first digit began in 1881 when Simon Newcomb noticed that the logarithmic tables were dirtier in the beginning than at the end. He concluded that table users were more likely to need decimal logarithms of numbers starting with a lower digit. He even hypothesized that the first significant digit c often appears in accordance with the logarithmic law, that is, with probability $P(c=n)=$ $\log (n+1)-\log n=\log (1+1 / n), n=1,2,3, \ldots, 9$ (Hladnik 2002, 140).

Newcomb's discovery was forgotten for quite a while, but then reemerged after more than fifty years. In 1938, Frank Benford, a physicist employed by a company for the distribution of electricity addressed this occurrence again (Hladnik 2002, 141).

At first, Benford's law was only applicable to mathematical and physical constants and to geographical data. Hal Varian stated in 1972 that the law could also be used to verify numbers in public planning decisions (Ramaswamy and Leavins 2007, 28).

In 1994, Nigrini proved that Benford's law could be used to detect deception or fraud. His research is based on the fact that individuals, due to psychological and aforementioned situations, create fraudulent numbers (Özer and Babacan 2013, 31). It is also assumed that he is the first researcher to have introduced and tested Benford's law in the field of financial statements in a comprehensive way in order to 
detect possible fraud in them (Durtschi, Hillison, and Pacini, 2004, 22).

Hill warned in 1996 that the reliability of Benford's law in detecting accounting irregularities is doubtful since it can provide a large number of false positive results. This means that certain false results could additionally trigger expensive investigations. Nigrini defends his definition by stating that the digital analysis of Benford's law provides a solid basis for the separation of suspicious data with a high degree of manipulation from data with a very low probability of manipulation, which is very important in further analyzes (Hales, Chakravorty, and Sridharan 2009, 615).

Benford's law has thus gradually gained increasing importance in the field of auditing and forensic accounting (Ramaswamy and Leavins 2007, 28). Until 1990, Benford's law was not recognized as a forensic accounting technique to detect possible fraud. Today, Benford's law, as an analytical technique, is one of the most popular digital processes and provides a unique method of data analysis. Benford's law allows forensic accountants to detect fraud, manipulation and other errors that may occur in the area of accounting data (Warshavsky 2010, 2).

\section{FEATURES OF BENFORD'S LAW}

Benford's law says that the likelihood of digit occurrence in different places in a number decreases logarithmically as the digit value increases. This is contrary to intuition, which states that the digits are evenly distributed. Therefore, Benford's law is primarily used as a means of identifying falsified data (Tolle and LaViolette 2000, 331). It is also used as a forensic tool to compare the actual frequency of the digits with the expected frequencies (Moore and Benjamin 2004, 5).

Large numbers are needed to effectively perform data analysis using Benford's law. It is recommended that the number has at least four digits. The first and first two digits of Benford's law are irrational numbers (Nigrini 2012, 23). However, for the implementation of the law, no minimum sample size is specified. For detecting irregularities in extreme digits, for example, it is recommended to have samples that exceed 1,00o data, while the detection of anomalies in early numbers may include samples that include less than 500 pieces of data (Hales, Chakravorty, and Sridharan 2009, 615).

It is important to note that when analyzing with Benford's law, positive and negative values are treated equally, as are values with decimal numbers (Skitek 2000, 19). The first leading figure is the first 
FIGURE 2

Benford's Law for the First Significant Digit (adapted from Nigrini 2012, 16)

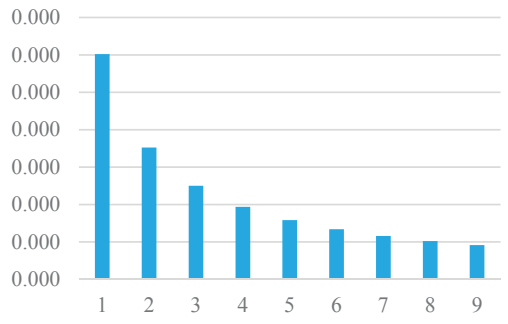

(not zero) number of a number that is at the far left. In the number 567.34 the first digit is 5 . In the number 0.0367 , the first digit is 3 because we discard the zeros. For a single integer number 6 , the first digit is 6 . With negative numbers we discard the minus sign, and in the number -62.97 the first digit is 6 (Kossovsky 2015, 8). Benford's law also describes the exact distribution for the second digit. The second digit is the second digit from the left. In the number 603 the second digit is 0 , in the number 0.0002867 the second digit is 8 , and in the number 1.653 .832 the second digit is 6 . For the second digit and the number of higher orders, it was found that the digit $\mathrm{o}$ is also included in the distribution (Kossovsky 2015, 21).

Regardless, Benford's law is a useful instrument in detecting fraud and manipulation in quantitative economic research. Benford's test does not provide preventive evidence of possible irregularities, but it can help identify which documents need to be examined and paid more attention (Todter 2009, 349). Boronico, Harris, and Teplitsky $(2014,33)$ argue that Benford's law can be applied to a number of internal audit areas. Examples include claims on insurance companies, corporate income tax, employee cost reports, invoices, paid receivables and fixed accounts.

The formulas for the order frequency of Benford's law are shown by $D_{1}$ for the first digit, $D_{2}$ for the second digit, and $D_{1} D_{2}$ for the first two digits. The probability of occurrence of the first digit is obtained by means of a mathematical formula (Nigrini 2012, 5):

$$
P\left(D_{1}=d_{1}\right)=\log \left(1+\frac{1}{d_{1}}\right) ; d_{1} \in\{1,2, \ldots, 9\} .
$$

Figure 2 shows the probability of an occurrence of digits in the first place in a number.

The probability of an occurrence of the second digit is obtained by means of a mathematical formula (Nigrini 2012, 5):

$$
\begin{gathered}
P\left(D_{2}=d_{2}\right)=\sum_{d_{1}}^{9} \log \left(1+\frac{1}{d_{1} d_{2}}\right) ; d_{2} \in\{0,1, \ldots, 9\} . \\
\text { MANAGEMENT } \cdot \operatorname{VOLUME} 14
\end{gathered}
$$


TABle 1 The Probability of an Occurrence of a Digit in Different Places in a Number

\begin{tabular}{lrrrr}
\hline Digit & \multicolumn{4}{c}{ Percentage } \\
\cline { 2 - 5 } & 1st place & 2nd place & 3rd place & 4th place \\
\hline 0 & & 11.968 & 10.178 & 10.018 \\
1 & 30.103 & 11.389 & 10.138 & 10.014 \\
2 & 17.609 & 10.882 & 10.097 & 10.010 \\
3 & 12.494 & 10.433 & 10.057 & 10.006 \\
4 & 9.691 & 10.031 & 10.018 & 10.002 \\
5 & 7.918 & 9.668 & 9.979 & 9.998 \\
6 & 6.695 & 9.337 & 9.940 & 9.994 \\
7 & 5.799 & 9.035 & 9.902 & 9.990 \\
8 & 5.115 & 8.757 & 9.864 & 9.986 \\
9 & 4.576 & 8.500 & 9.827 & 9.982 \\
\hline Total & 100.000 & 100.000 & 100.000 & 100.000 \\
\hline
\end{tabular}

Notes Adapted from Nigrini $(2012,6)$.

FIGURE 3

A Graphic Representation of

Probability for the Selected

Combination of the First Two Digits in a Number (adapted from Gunnel and Todter 2009, 275)

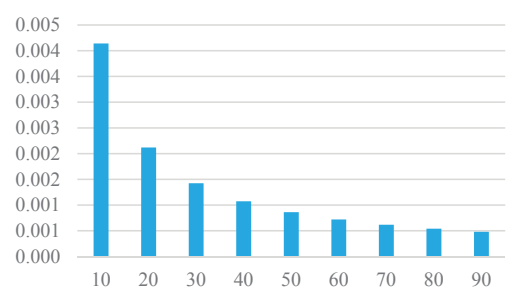

The probability for the occurrence of a digit in the first four places in the number is shown in table 1.

Nigrini $(2012,5)$ states that the probability of an occurrence of the first two digits in a number is obtained by means of a mathematical formula:

$$
P\left(D_{1} D_{2}=d_{1} d_{2}\right)=\log \left(1+\frac{1}{d_{1} d_{2}}\right) ; d_{1} d_{2} \in\{10,11, \ldots, 99\} .
$$

The probability of an occurrence of the selected combination of the first two digits in the number is shown in table 2.

Figure 3 shows the probability of an occurrence of the first two digits in a number.

The most common tests are the first digit test, the second digit test, and the first two digits test. The first digit test compares the actual probability of an occurrence of a number on the first place with the theoretical probability according to the Benford's law. This test will guide the forensic accountant in the right direction and indicate the 
TABLE 2 The Probability of an Occurrence of a Digit in Different Places in a Number (percentage)

\begin{tabular}{|c|c|c|c|c|c|c|c|c|c|c|}
\hline \multirow{2}{*}{$\begin{array}{l}\text { 2nd } \\
\text { place }\end{array}$} & \multicolumn{9}{|c|}{ 1st place } & \multirow[t]{2}{*}{$\Sigma$} \\
\hline & 1 & 2 & 3 & 4 & 5 & 6 & 7 & 8 & 9 & \\
\hline 0 & 4.139 & 2.119 & 1.424 & 1.072 & 0.860 & 0.718 & 616 & 0.540 & 0.480 & 11.968 \\
\hline 1 & 3.779 & 2.020 & 1.379 & 1.047 & 0.843 & 0.706 & 0.607 & 533 & 475 & 11.389 \\
\hline 2 & 3.476 & 1.931 & 1.336 & 1.022 & 0.827 & 0.695 & 0.599 & 0.526 & 0.470 & 10.882 \\
\hline 3 & 3.218 & 1.848 & 1.296 & 0.998 & 0.812 & 0.684 & 0.591 & 0.520 & 0.464 & 10.433 \\
\hline 4 & 2.996 & 1.773 & 1.259 & 6 & 0.797 & 3 & 83 & 4 & 0.460 & 10.031 \\
\hline 5 & 2.803 & 1.703 & 1.223 & 55 & 3 & 3 & 75 & 0.508 & 55 & 568 \\
\hline 6 & 2.633 & 1.639 & 1.190 & 0.934 & 0.769 & 0.653 & 0.568 & 0.502 & 450 & 9.337 \\
\hline$\gamma$ & 2.482 & 1.579 & $1.15^{8}$ & 0.914 & 0.755 & 0.643 & 0.560 & 0.496 & 0.445 & 9.035 \\
\hline 8 & 2.348 & 1.524 & 1.128 & 0.895 & & 0.634 & 553 & 0.491 & 0.441 & 8.757 \\
\hline 9 & 2.228 & 1.472 & 1.100 & 0.877 & 0 & 0.625 & 0.546 & 0.485 & 0.436 & 8.500 \\
\hline 2 & .103 & 17.609 & .494 & 9.691 & 7.918 & 6.695 & 5.799 & 5.115 & 4.576 & 00.000 \\
\hline
\end{tabular}

Notes Adapted from Gunnel and Todter (2009, 275).

possible anomaly of the data. The second digit test is therefore similar to the first digit test and helps the forensic accountant to identify any irregularities in the analyzed data. The first two digits test is a somewhat more in-depth investigation, as it checks the likelihood of the first two digits in the number. The aforementioned test identifies any irregularities that are not detected by the first digit test or the second digit test (Warshavsky 2010, 3).

General statistical tests can be used to verify the correctness of Benforod's law. The Z-test is used for the graphic interpretation of Benford's law. The formula takes into account the absolute size of the difference, the number of records and the extent of the expected share. In order to check Benford's distribution, we usually use a $95 \%$ reliability, which extends over the interval \pm 1.960 (Nigrini 2012, 82). The formula is summarized by Fleiss (1981) and is shown in the equation below.

$$
Z=\frac{|\mathrm{AP}-\mathrm{EP}|-\frac{1}{2 N}}{\sqrt{\frac{\mathrm{EP}(1-\mathrm{EP})}{N}}},
$$

where AP (Actual Proportion) represents the actual share, the EP (Expected Proportion) is the expected share and $N$ is the number of records.

The last term in the numerator $(1 / 2 N)$ is a correction and is used only if it is smaller than the first term in the numerator (Nigrini 2012, 150). 
table 3 Test of the First Digit of Mercator d.d. Company from 2012 to 2017

\begin{tabular}{lrrrrr}
\hline 1st significant digit & $(1)$ & $(2)$ & $(3)$ & $(4)$ & $(5)$ \\
\hline 1 & 80 & 0.30103 & 0.25723 & -0.04380 & 1.62192 \\
2 & 82 & 0.17609 & 0.26367 & 0.08757 & 3.98017 \\
3 & 36 & 0.12494 & 0.11576 & -0.00918 & 0.40403 \\
4 & 25 & 0.09691 & 0.08039 & -0.01652 & 0.88919 \\
5 & 25 & 0.07918 & 0.08039 & 0.00120 & -0.02630 \\
6 & 21 & 0.06695 & 0.06752 & 0.00058 & -0.07270 \\
7 & 16 & 0.05799 & 0.05145 & -0.00655 & 0.37253 \\
8 & 19 & 0.05115 & 0.06109 & 0.00994 & 0.66704 \\
9 & 7 & 0.04576 & 0.02251 & -0.02325 & 1.82647 \\
\hline Total & 311 & & & & 1.07359 \\
Average & & & & & \\
\hline
\end{tabular}

Notes Column headings are as follows: (1) sampling frequency (Mercator d.d.), (2) frequency (Mercator d.d.), (3) frequency - Benford's law, (4) difference, (5) Zstatistics.

\section{Analysis of the Financial Statements of the Mercator d.d. Company with the Benford Law}

The financial statements of Mercator d.d. are publicly available on the AJPES website. From the Ajpes website, we obtained data on financial statements for a period of six years $(2012,2013,2014,2015$, 2016 and 2017). The data was imported into Excel. The imported data was then merged in Excel after each year and analyzed with Benford's law.

The financial statements (balance sheet and profit and loss account) of the Mercator d.d. company contained a total of 311 pieces of data from 2012 to 2017. This is a large sample of data, which enables a greater reliability of Benford's law. In the financial statements, we found that duplicate data for individual items appear. Duplicates are present mainly due to different levels of items in the financial statements. We did not remove them, as this would have reduced the effectiveness of further analysis. The first digit test of the financial statements of the Mercator d.d. company over the entire six-year period is presented below.

Figure 5 shows that the financial statements are consistent with Benford's law, but do not fully follow Benford's law. For the interpretation of the graphic representation, we have to perform the $Z$-test. At $95 \%$ reliability, we claim that digit 2 deviates from Benford's law, since the digit exceeds the critical value of \pm 1.960 . This leads us to the conclusion that this number should be given greater attention.

Figure 5 shows that the financial statements are consistent with 
FIGURE 4

Graphic Presentation of the First Digit of the Mercator d.d. Company from 2012-2017 (blue Benford, red Mercator)

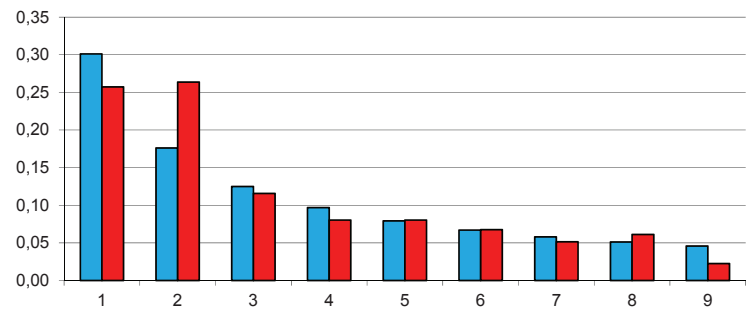

TABLE 4 Test of the Second Digit of Mercator d.d. Company from 2012 to 2017

\begin{tabular}{lrrrrr}
\hline 2st significant digit & $(1)$ & $(2)$ & $(3)$ & $(4)$ & $(5)$ \\
\hline 0 & 33 & 0.11968 & 0.10714 & -0.01254 & 0.59009 \\
1 & 33 & 0.11389 & 0.10714 & -0.00675 & 0.28306 \\
2 & 40 & 0.10822 & 0.12987 & 0.02165 & 1.13137 \\
3 & 26 & 0.10433 & 0.08442 & -0.01991 & 1.05011 \\
4 & 30 & 0.10031 & 0.09740 & -0.00291 & 0.07501 \\
5 & 38 & 0.09668 & 0.12338 & 0.02670 & 1.48901 \\
6 & 40 & 0.09337 & 0.12987 & 0.03650 & 2.10374 \\
7 & 20 & 0.09035 & 0.06494 & -0.02541 & 1.45645 \\
8 & 30 & 0.08757 & 0.09740 & 0.00983 & 0.50968 \\
9 & 18 & 0.08500 & 0.05844 & -0.02656 & 1.56916 \\
Total & 308 & 100.00000 & 100.00000 & & \\
\hline Average & & & &
\end{tabular}

Average

1.02577

Notes Column headings are as follows: (1) sampling frequency (Mercator d.d.), (2) frequency (Mercator d.d.), (3) frequency - Benford's law, (4) difference, (5) Zstatistics.

Benford's law, but do not fully follow Benford's law. For the interpretation of the graphic representation, we have to perform the $Z$-test. At 95\% reliability, we claim that the digit 6 deviates from Benford's law, since the digit exceeds the critical value of \pm 1 .960. This leads us to the conclusion that this number should be given greater attention.

More precise results were obtained using the first two digits test. Figure 6 shows that the financial statements are consistent with Ben-

FIGURE 5

Graphic Presentation of the Second Digit of the Mercator d.d. Company from 2012-2017 (blue Benford, red Mercator)

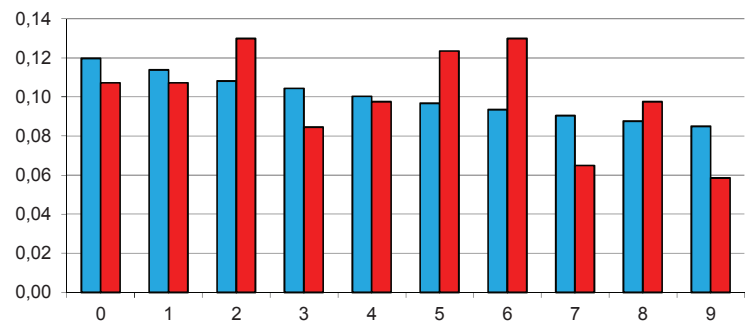

MANAGEMENT $\cdot$ VOLUME 14 


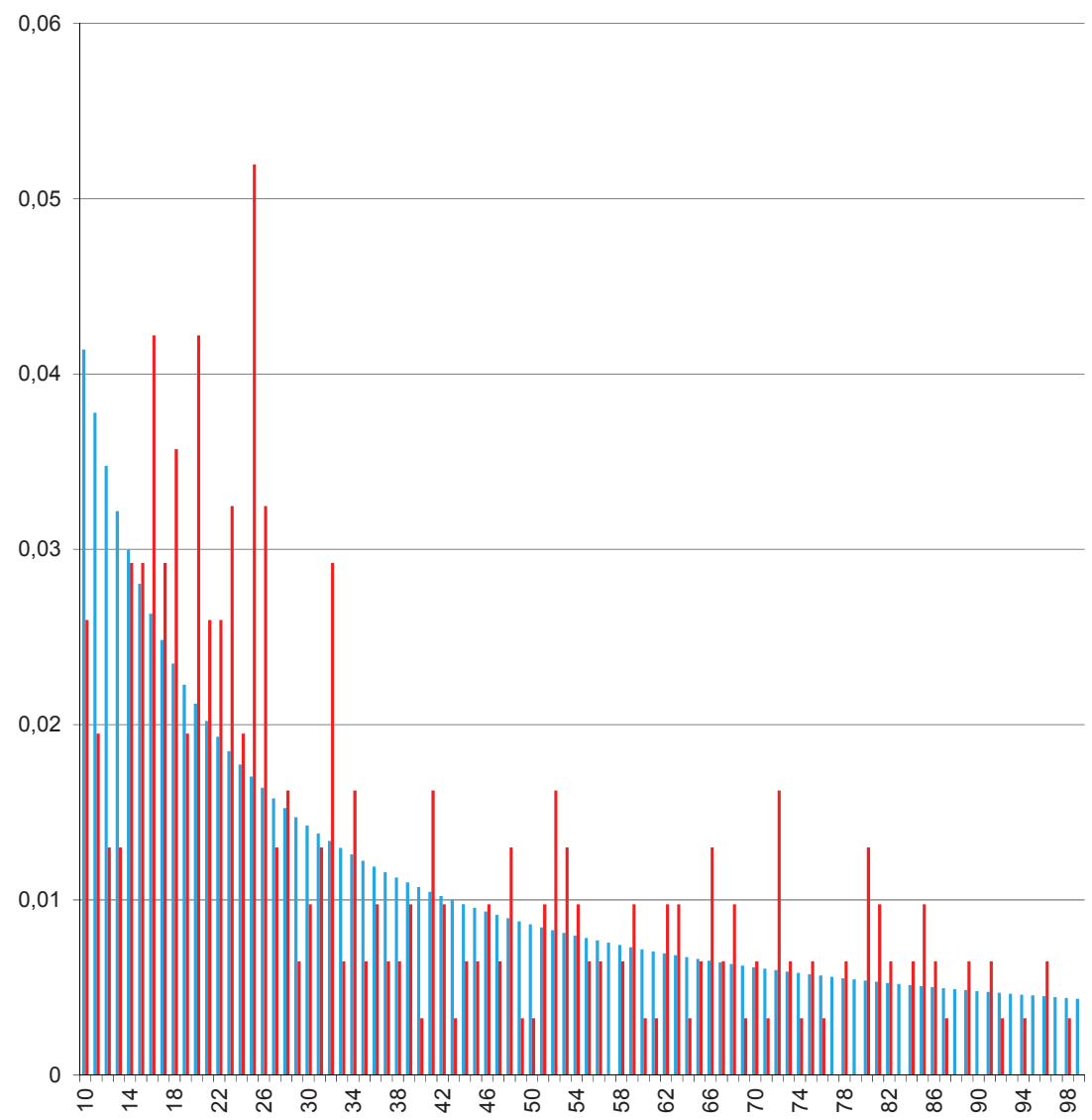

FIgURe 6 Graphic Presentation of the First Two Digits of the Mercator d.d. Company from 2012-2017

ford's law, but do not fully follow Benford's law. For the interpretation of the graphic interpretation, we have to perform the $Z$-test. At $95 \%$ reliability, we claim that the digits 20, 25, 26 and 32 deviate from Benford's law because the numbers exceed the critical value of \pm 1.960 . This leads us to the conclusion that these numbers need to be given greater attention.

\section{Conclusion}

Benford's law describes the distribution of the first significant digits in data that do not have any apparent connection with each other. The phenomenon was initially discovered at random, but today it has numerous uses in various fields, especially when verifying that 
certain data, such as financial statements, have been falsified. Benford's law is just one of the tools used to detect irregularities, which can also be used in the field of data verification in financial statements. It is a simple, objective and effective deductive digital analysis, which is widely used abroad, but quite unknown in practice and used very rarely in Slovenia.

Benford's law is very useful in terms of detecting irregularities in financial statements. If the first digits are distributed in a different way than they should be, then on the basis of the test we can determine whether this is fraud or an error. Using the Benford Act, we analyzed the credibility of the Mercator d.d. company's financial statements. In the first digit test, we came to the conclusion that the financial statements are not in accordance with Benford's law. When using the first digit test, we found that digit 2 deviates from Benford's law. In the second digit test, we found that the financial statements were not in compliance with Benford's law. We found that the second digit 6 deviates from Benford's law. In the first two digits test we came to the conclusion that the financial statements are not in compliance with Benford's law. We found that the first two digits 20, 25, 26 and 32 differ from Benford's law. This leads us to the conclusion that greater attention needs to be paid to these numbers. Based on the results, it can be argued that the figures in the financial statements are not distributed according to Benford's law, so we can conclude that the possibility of fraud exists in the financial statements.

\section{References}

ACFE. 2014. Report to the Nations on Occupational Fraud and Abuse. Austin, TX: ACFE.

Boronico, J., P. Harris, and F. Teplitsky. 2014. 'Benford's Law and Applications for the International Auditor.' Internal Auditing 29 (6): 32-36.

Durtschi, C., W. Hillison, and C. Pacini. 2004. 'The Effective Use of Benford's Law to Assist in Detecting Fraud in Accounting Data.' Journal of Forensic Accounting 5:17-34.

Fleis, J. L. 1981. Statistical Methods for Rates and Proportions. London: Wiley.

Gunnel, S., and K.-H. Todter. 2009. 'Does Benford's Law Hold in Economic Research and Forecasting?' Empirica 36 (3): 273-92.

Hales, D., S. Chakravorty, and V. Sridharan. 2009. 'Testing Benford's Law for Improving Supply Chain Decision-Making: A Field Experiment.' International Journal of Production Economics 122 (2): 606-18.

Hladnik, M. 2002. 'Benfordov zakon ali problem prve števke.' Obzornik za matematiko in fiziko 49 (5): 140-47. 
Koletnik, F. 2009. Zunanje revidiranje. Maribor: Ekonomsko-poslovna fakulteta.

Koletnik, F., and I. Kolar. 2008. Forenzično računovodstvo. Ljubljana: Zveza računovodij, finančnikov in revizorjev Slovenije.

Kossovsky, A. 2015. Benford's Law: Theory, the General Law of Relative Quantities, and Forensic Fraud Detection Applications. Singapore: World Scientific.

Mednarodni standard revidiranja. 2009. Ljubljana: Zveza računovodij, finančnikov in revizorjev Slovenije.

Moore, G., and C. Benjamin. 2004. 'Using Benford's Law for Fraud Detection.' Internal Auditing 19 (1): 4-9.

Nigrini, M. 2012. Benford's Law: Applications for Forensic Accounting, Auditing, and Fraud Detection. Hoboken, NJ: John Wiley.

Nigrini, H., and L. Mittermaier. 1997. 'The Use of Benford's Law as an Aid in Analytical Procedures.' A Journal of Practice and Theory 16 (2): 52-62.

Özer, G., and B. Babacan. 2013. 'Benford's Law and Digital Analysis: Application on Turkish Banking Sector.' Business and Economics Research Journal 4 (1), 29-41.

Ramaswamy, V., and J. Leavins. 2007. 'Continuous Auditing, Digital Analysis, and Benford's Law.' Internal Auditing 22 (4): 25-31.

Skitek, D. 2000. 'Uporaba Benfordovega zakona pri odkrivanju prevar v računovodskih izkazih.' Revizor 11 (9): 7-24.

Todter, K. 2009. 'Benford's Law As an Indicator of Fraud in Economics.' German Economic Review 10 (3): 339-51.

Tolle, C. B., and R. LaViolette. 2000. 'Do Dynamical Systems Follow Benford's Law? Chaos 10 (2): 331-6.

Warshavsky, M. 2010. 'Applying Benford's Law in Financial Forensic Investigations.' National Litigation Consulants Review 10 (2): 1-4.

This paper is published under the terms of the Attribution-

NonCommercial-NoDerivatives 4.o International (CC BY-NC-ND 4.0)

License (http://creativecommons.org/licenses/by-nc-nd/4.o/). 